\title{
Study of Hepatic Dysfunction in Dengue Fever: Does it Tell You the Prognosis?
}

\author{
Sangita Kamath $^{* 1}$, Tauheed Ahmed ${ }^{2}$ \\ ${ }^{1}$ Specialist, Department of Medicine, Tata Main Hospital, Jamshedpur, India; dr.sdkamath@tatasteel.com \\ ${ }^{2} 3^{\text {rd }}$ Year DNB Student, Department of General Medicine, Tata Main Hospital, Tata Steel, Jamshedpur; \\ tauheed.90@gmail.com
}

*Corresponding Author: Sangita Kamath; dr.sdkamath@tatasteel.com

Received 30 March 2021;

Accepted 20 April 2021;

Published 14 May 2021

\begin{abstract}
Introduction: Dengue is the most rapidly spreading mosquito-borne viral disease. Liver is the most commonly affected organ and manifests as asymptomatic transaminitis to acute liver failure. Aim: (1) To study the clinical and biochemical profile of liver involvement. (2) To find the association between severity of hepatic dysfunction, morbidity and mortality in the admitted patients. Method and Material: This was a prospective study involving confirmed dengue fever cases admitted in Tata Main Hospital from January 2018 to December 2019 . Cases were classified into non-severe dengue and severe dengue based on 2009 WHO classification. Severity of hepatic dysfunction was divided into grades A, B, C and D and correlation with various outcomes which included length of stay, complications and mortality was studied through relevant investigations. Results: Out of the 175 cases, Non-severe Dengue (NSD) was seen among $72.6 \%$ patients while severe dengue (SD) in 28.5\% patients. Normal liver function was found in $68.6 \%$, Grade B liver injury in $8 \%$ while Grade C and Grade D liver injury in $16.6 \%$ and $16.8 \%$ patients respectively. Mean AST levels were found to be higher than those of ALT levels. Longer hospital stay, complications like shock, acute kidney injury (AKI), thrombocytopenia and mortality were significantly more in patients with higher grades of liver dysfunction ( $\mathrm{p}=0.03$ ), while ARDS and MODS were seen only in patients with Grade C and Grade D liver injury. Conclusion: AST and ALT levels were statistically higher in Dengue fever patients with worse outcome. They can thus, serve as prognostic markers of severe Dengue.
\end{abstract}

Keywords: complications, dengue, fever, enzymes, liver dysfunction

\section{Introduction}

Dengue is the most common cause of arboviral disease globally. Around 2.5 billion people in 125 endemic countries are believed to be susceptible ${ }^{[1,2]}$. Infection with the dengue virus (DENV) results in an undifferentiated viral fever like illness to "severe" dengue (Group C), as categorized by World Health Organization (WHO) in 2009, which includes the dengue hemorrhagic fever (DHF) and dengue shock syndrome (DSS) ${ }^{[3]}$.

Involvement of the liver leading to hepatic dysfunction is a well-recognized complication of dengue ${ }^{[4-6]}$. The spectrum of involvement includes asymptomatic elevation of hepatic transaminases (anicteric hepatitis) to the occurrence of acute liver failure ${ }^{[5,7,8]}$. Severe elevation of liver enzymes may be confused for acute viral hepatitis A, B, or C. There have been few studies on the hepatic dysfunction in dengue fever in adults from the eastern part of the country. Hence, we under took this study during a recent outbreak of dengue fever in Jamshedpur with an aim

1. To evaluate the clinical and biochemical profile of liver involvement
2. To find the association between the severity of hepatic dysfunction and morbidity and mortality in the admitted patients.

\section{Methods and materials}

This was a prospective observational study. Patients diagnosed with dengue fever from January 2018 - December 2019 were recruited by consecutive sampling method. The study population constituted patients admitted in the medical wards, and critical care unit in Tata Main Hospital, Jamshedpur. The study participants who fulfilled inclusion criteria were included.

\section{Inclusion criteria}

1. Patients with age $\geq 12$ year, both sexes

2. Any febrile illness of $\leq 5$ days with clinical features of myalgia, arthralgia, headache, retro-orbital pain, skin rash, bleeding from any site with NS1 antigen positive by ELISA and/or IgM antibody detected by ELISA / card test 


\section{Exclusion criteria}

Patients with other diseases causing deranged liver function like

1. Malaria

2. Alcoholic liver disease

3. Patients with known chronic liver disease

4. NS1 antigen positive only by card test and negative by ELISA

5. Pregnant females

\section{Methodology}

Informed consent was taken from all the subjects. Demographic characteristics, clinical features like the history of onset of illness, progression, duration of various symptoms were noted. General physical examination with recording of the vital parameters were done every eight hours a day. Blood investigations done included complete blood picture including platelet count, liver function tests (serum bilirubin, Alanine aminotransferase (ALT), Aspartate aminotransferase (AST), Alkaline Phosphatase (ALP), serum proteins (albumin and globulin), prothrombin time, international normalized ratio (INR) and blood urea and serum creatinine. These were done using automated biochemical analyzers, on the day of admission and repeated every 48 hours till discharge or death. Chest radiography, ultrasound examination of chest and abdomen with pelvis were done for evidence of capillary leak on the first or second day of admission and repeated if needed.

Severity of dengue infection was classified according to the 2009 WHO guidelines ${ }^{[3]}$. Accordingly, patients who had detectable fluid in the pleural cavities by ultrasound scanning with respiratory distress, severe bleeding, shock (Dengue shock syndrome) or who had liver transaminases above $>1000 /$ IU were grouped as having Severe Dengue (SD). Those who had dengue with warning signs or without warning signs were classified as having non-severe dengue (NSD).

Grading of the liver injury ${ }^{[9]}$
Grade A - Normal liver function tests

Grade B - At least one of the enzymes raised up to 2 times the ULN (upper normal limit)

Grade C - One of the enzymes raised to $>2 \mathrm{X}$ ULN to $10 \mathrm{X} \mathrm{ULN}$

Grade D - At least one of the enzymes $>10$ X ULN/evidence of liver failure/ hepato-renal involvement (high creatinine)

The degree of hepatic dysfunction and the various outcomes were compared.

Outcomes measured were length of stay (LOS), complications like Dengue Hemorrhagic Fever (DHF), Dengue Shock Syndrome (DSS), thrombocytopenia, Acute Respiratory Distress Syndrome (ARDS), Acute Kidney Injury (AKI) and Disseminated Intravascular Coagulation (DIC) and mortality.

\section{Statistical analysis}

The qualitative variables are described in the form of proportions and quantitative variables are described in the terms of mean, median, range and standard deviation. Data was checked for normality before applying appropriate tests of significance. Data analysis was done with Statistical Package for Social Sciences (SPSS IBM) version 21.0. Required univariate and bivariate analysis were done. Significance of difference in means was calculated using independent $\mathrm{t}$ test and Chi square tests. Significance of $\mathrm{p}$ value was taken as $\mathrm{p}<0.05$. Ethical permission was obtained from ethics committee for Post Graduate Studies, Tata Main Hospital.

\section{Results}

A total of 175 subjects were enrolled, of which 92(52.6\%) were males and $83(47.4 \%)$ were females, male to female ratio being 1.1:1. Their age ranged from $16-70$ years with mean $( \pm$ SD) being $32( \pm 13.06)$ years. While $89(50.9 \%)$ were in $16-30$ years age group, only $11(6.3 \%)$ were beyond the sixth decade of life. The age and sex distribution of cases is as shown in the Figure 1.

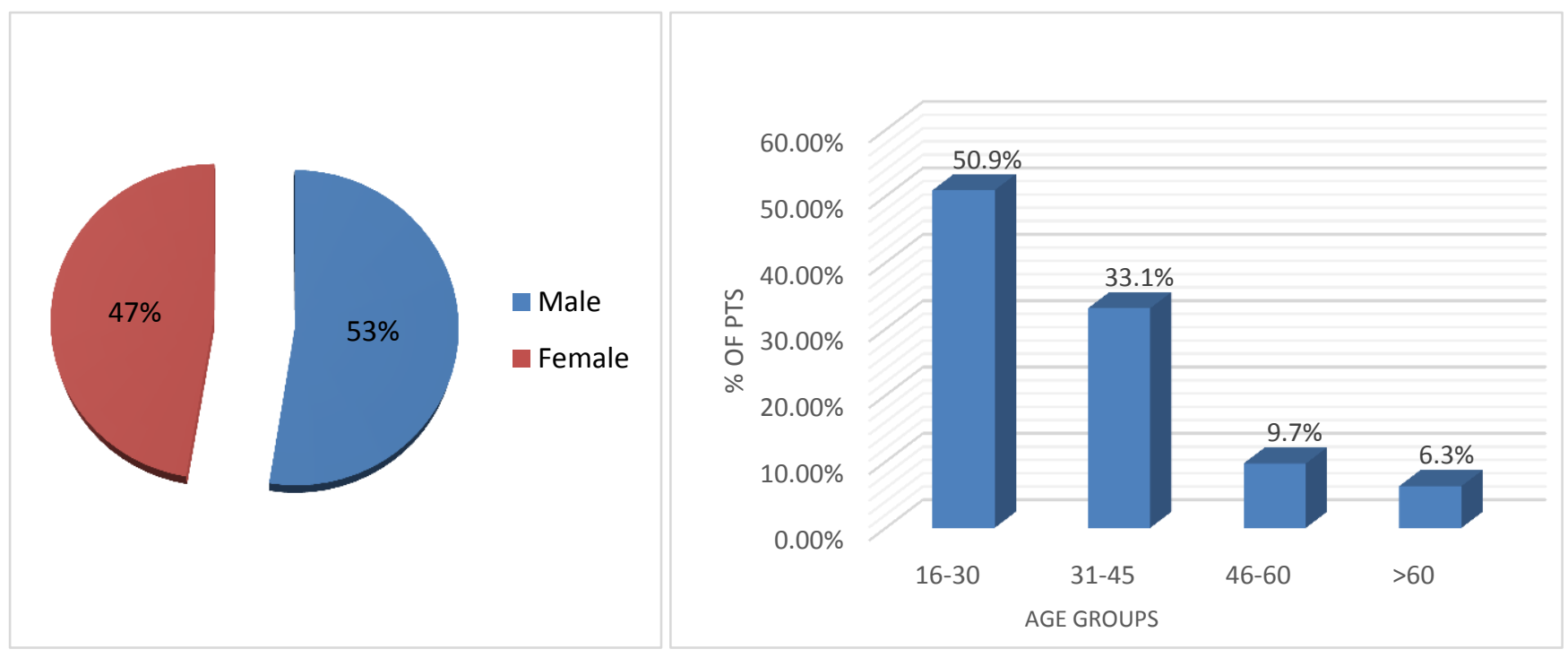

Figure 1: Sex and age distribution of the cases $(n=175)$

Among the clinical manifestations, fever was the commonest presentation and was found in 174 (99.4\%) patients. Mean duration of fever prior to hospital admission was $4.3 \pm 1.1$ days. Macular, erythematous rash, distributed all over the body was noted in 12 $(6.9 \%)$ patients. Vomiting with nausea was the most common gastrointestinal symptom found in $84(48 \%)$ patients followed by abdominal pain in $45(25.7 \%)$ patients, abdominal distension in 33 (18.9\%) patients, diarrhea in $11(6.9 \%)$ patients and gastrointestinal bleed (black stools and coffee colored vomitus) in 13 (7.4\%) patients (Figure 2). 


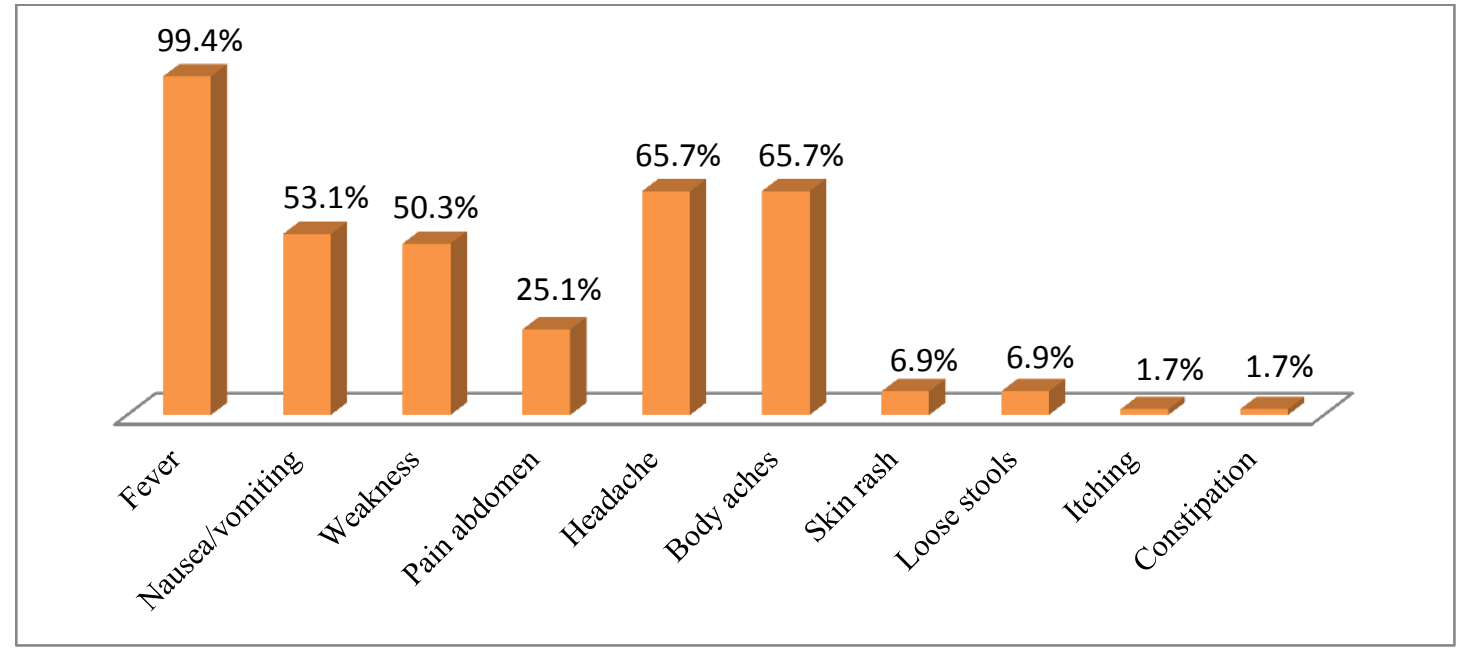

Figure 2: Presenting symptoms of admitted patients $(n=175)$

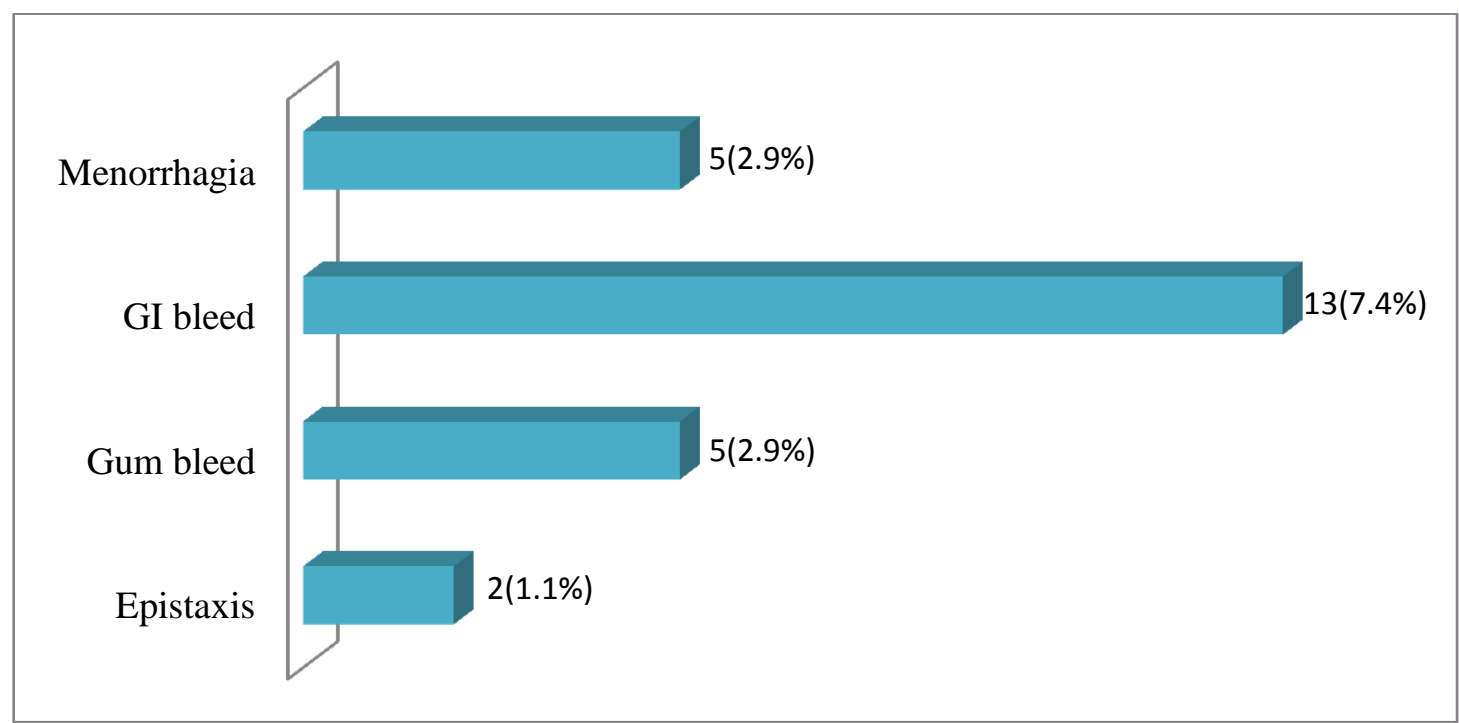

Figure 3: Hemorrhagic manifestations among the study participants. $(n=175)$

Bleeding manifestations seen were as depicted in the bar graph above (Figure 3). Gastrointestinal bleed was the most common hemorrhagic manifestation seen. Based on the 2009 WHO guidelines, NSD was seen among $130(74.3 \%)$ patients while SD in $48(28.5 \%)$ patients of which DHF was found in $26(14.9 \%)$, DSS in $19(10.9 \%)$ patients while $3(1.8 \%)$ had only elevation of transaminases to more than $1,000 \mathrm{U} / \mathrm{L}$. The average duration of hospital stay was 5.39 days. ICU admission was required in $13(7.4 \%)$ of study participants.

\section{Profile of liver function tests during the hospital stay}

Liver enzymes: Among the 175 participants, normal liver function (Grade A) was found in 42 (24\%), Grade B liver injury was found in $85(48.6 \%)$ patients, Grade C in $29(16.6 \%)$ patients and Grade D in $19(10.9 \%)$ patients on admission (Figure 4). 7 (4\%) patients had elevation of ALT more than 1,000U/L while 11 (6.3\%) patients had AST elevation to more than 1000U/L. Elevation of both the liver enzymes to above $1,000 \mathrm{U} / \mathrm{L}$ was seen in $7(4 \%)$ patients.

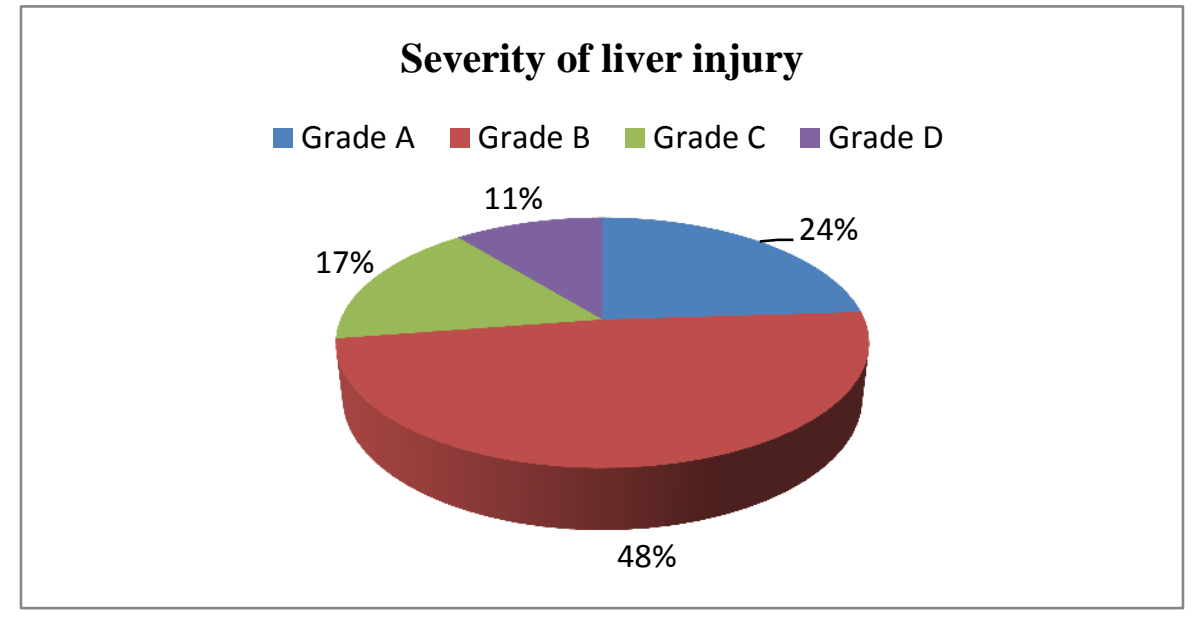

Figure 4: Degree of elevation of liver enzymes $(n=175)$ 
The average ALT and AST levels on admission were 204( \pm 430$)$ $\mathrm{U} / \mathrm{L}$ and $388( \pm 933) \mathrm{U} / \mathrm{L}$ respectively while the maximum values were $3413.7 \mathrm{U} / \mathrm{L}$ and $5999.4 \mathrm{U} / \mathrm{L}$ respectively. The peak levels of liver enzymes were found from 5 th to 9 th day. On average, peak liver enzymes levels were found on $6.6( \pm 2.4)$ days. The peak average $( \pm$ SD) of ALT and AST levels were 272( \pm 589$)$ and $519( \pm 1360)$ respectively while the maximum peak values of ALT and AST seen were 4300.5U/L and 12,270U/L respectively (Figure 5). Levels then declined after 10th day of illness. Raised ALP levels was seen in 46 (26.3\%) study participants. All these patients

\section{ALT levels (U/L)}

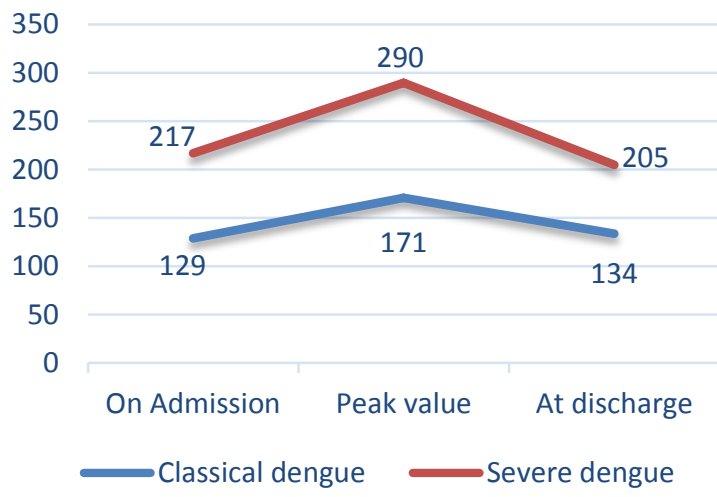

also had elevation of AST with or without rise of ALT. Average ALP levels was $136 \pm 253 \mathrm{U} / \mathrm{L}$. However, none of the patients showed obstructive pattern of enzyme elevation. AST level was elevated more than ALT in $112(64 \%)$ of the patients while ALT levels was more than AST in only $16(9.14 \%)(\mathrm{OR}=7,95 \% \mathrm{CI} 3.98$ to $12, \mathrm{p}<0.0001)$. In the patients with elevated liver enzymes, mean AST levels (393.6U/L) were found to be higher than mean ALT levels (223.6U/l), the ratio of AST/ALT being >1. Both AST and ALT levels at admission and peak levels, were much higher in patients with SD than in those with NSD (Figure 5).

\section{AST levels (U/L)}

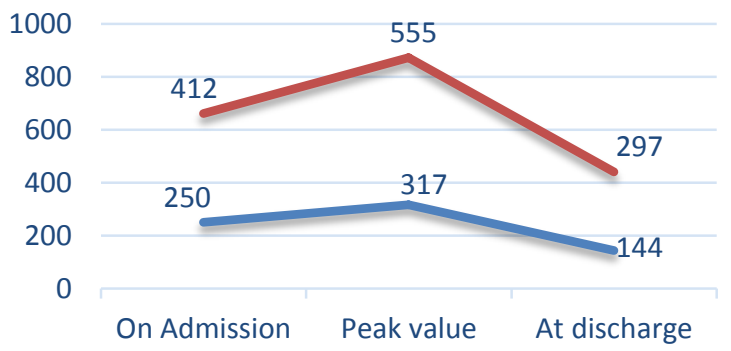

$\longrightarrow$ Classical dengue $\longrightarrow$ Severe dengue

Figure 5: Changes in serum transaminase levels throughout the course of illness in patients $(n=175)$

Table 1 shows the difference in clinical characteristics of patients with normal and elevated liver enzymes. Duration of fever, abdominal pain, bleeding manifestations, pleural effusion and shock were significantly higher in patients with elevated liver enzymes $(\mathrm{P}<0.001)$ while ascites was found only in patients with elevated liver enzymes. Vomiting, however, though apparently more common in patients with elevated liver enzymes, was not of statistical significance $(\mathrm{p}=0.1)$. SD was significantly more common in patients with elevated liver enzymes $(\mathrm{p}<0.0001)$. It was observed that patients with normal liver enzymes had NSD $(\mathrm{p}<0.001)$.

Table 1: Clinical characteristics of patients with normal and elevated liver enzymes

\begin{tabular}{|l|l|l|l|l|l|}
\hline Clinical findings & $\begin{array}{l}\text { Elevated liver enzymes } \\
(\mathbf{n = 1 3 3 )}\end{array}$ & $\begin{array}{l}\text { Normal liver } \\
\text { enzymes (n=42) }\end{array}$ & $\begin{array}{l}\text { Odds ratio } \\
(\mathbf{O R})\end{array}$ & $\mathbf{9 5 \%}$ CI & P value \\
\hline Duration of fever & $5.6 \pm 3.5$ days & $2.4 \pm 1.6$ days & 5.454 & 1.026 to 28.995 & 0.04 \\
\hline Vomiting & $35(21 \%)$ & $49(29.4 \%)$ & 1.558 & 0.909 to 2.670 & 0.106 \\
\hline Abdominal pain & $36(21.6 \%)$ & $14(8.4 \%)$ & 5.61 & 2.800 to 11.24 & $<0.0001$ \\
\hline Bleeding manifestations & $22(13.2 \%)$ & $3(1.8 \%)$ & 16 & 4.59 to 55.7 & $<0.0001$ \\
\hline Hepatomegaly & $21(12.6 \%)$ & $13(7.4 \%)$ & 3.52 & 1.645 to 7.549 & 0.0012 \\
\hline Pleural effusion & $34(21.7 \%)$ & $0(0 \%)$ & 149.8 & 9.02 to 2488.1 & 0.0005 \\
\hline Shock & $19(10.8 \%)$ & $3(1.8 \%)$ & 13.81 & 3.92 to 48.65 & $<0.0001$ \\
\hline NSD & & $119(68 \%)$ & 0.181 & 0.088 to 0.373 & $<0.0001$ \\
\hline SD $^{\#}$ & $10(6 \%)$ & $1(0.6 \%)$ & 98.18 & 13.19 to 730.7 & $<0.0001$ \\
\hline
\end{tabular}

NSD - Non-severe Dengue SD - Severe Dengue

Table 2: Pattern of elevation of liver enzymes in survivors and non-survivors

\begin{tabular}{|c|c|c|c|c|c|}
\hline S no & Variables & Mean \pm SD & $t$ value & $95 \% \mathrm{CI}$ & $P$ value \\
\hline 1. & $\begin{array}{l}\text { AST } \\
\text { Non-survivor } \\
\text { Survivor }\end{array}$ & $\begin{array}{l}5067 \pm 1452 \\
307 \pm 672\end{array}$ & 11.91 & $399-3971$ & 0.000001 \\
\hline 2. & $\begin{array}{l}\text { ALT } \\
\text { Non-survivor } \\
\text { Survivor }\end{array}$ & $\begin{array}{l}2291 \pm 973 \\
168 \pm 316\end{array}$ & 11.0 & $192-1742$ & 0.00001 \\
\hline 3. & $\begin{array}{l}\text { ALP } \\
\text { Non-survivor } \\
\text { Survivor }\end{array}$ & $\begin{array}{l}344 \pm 47.8 \\
136 \pm 25.4\end{array}$ & 1.413 & $-82.5-498.16$ & 0.15 \\
\hline 4. & $\begin{array}{l}\text { Serum Albumin } \\
\text { Non-survivor } \\
\text { Survivor }\end{array}$ & $\begin{array}{l}2.6 \pm 0.74 \\
3.9 \pm 0.62\end{array}$ & -3.66 & $-2.05-0.616$ & 0.00001 \\
\hline
\end{tabular}


Higher levels of serum transaminases (both AST and ALT) were significantly associated with mortality $(\mathrm{P}<0.05)$ and hence, severe Dengue (SD) while the ALP level though was apparently was higher in non-survivors, the difference was not statistically significant $(\mathrm{p}=0.15)$ (Table 2$)$.

\section{Changes in serum bilirubin and albumin}

Average total serum bilirubin level on admission was $0.85( \pm 0.7)$ $\mathrm{mg} / \mathrm{dl}$ while the maximum value observed was $5.57 \mathrm{mg} / \mathrm{dl}$. Only 4 (2.3\%) patients had serum bilirubin $>5 \mathrm{mg} / \mathrm{dl}$ on presentation. The degree of rise in serum bilirubin did not correlate with the degree of elevation of liver enzymes. International Normalized Ratio (INR) was more than 3 in $3(1.7 \%)$ patients. Maximum value observed was 5.64 while the average $( \pm \mathrm{SD})$ was $1.68( \pm 3.8)$. The average $( \pm \mathrm{SD})$ serum albumin levels on admission was $3.69( \pm 0.53)$ $\mathrm{gm} / \mathrm{dl}$. The serum albumin levels were significantly lower in nonsurvivors, while the values were normal $(2.6 \pm 0.74$ vs $3.9 \pm 0.62)$ in those who survived $(\mathrm{p}=0.00)$.

\section{Radiological assessment}

Ultrasound of the abdomen revealed hepatomegaly in $34(19.4 \%)$ patients, splenomegaly in $13(7.4 \%)$ patients, ascites in $43(24.6 \%)$ patients and gall bladder wall edema in 7(4\%) patients. Ascites was detected clinically in $13(7.4 \%)$ patients and on ultrasound of abdomen in 30(17.1\%) patients. Chest radiography revealed pleural effusion in $34(19.4 \%)$ patients and pulmonary edema in $6(3.4 \%)$ patients. Ascites with pleural effusion was seen in all the nonsurvivors $(\mathrm{P}<0.05)$ while were seen in $42(24 \%)$ of the survivors and $34(19.4 \%)$ of the cases of SD.

\section{Outcomes}

172 patients recovered. $3(1.7 \%)$ patients expired resulting in casefatality rate of $1.8 \%$ of which 1 was male and 2 were females. $11(6.3 \%)$ patients with grade D liver injury required transfer to ICU. Amongst the complications, DHF, DSS, AKI, DIC, ARDS, MODS, bleeding complications and thrombocytopenia (platelets $<50,000 / \mathrm{cu} \mathrm{mm}$ ) were seen respectively in $25(14.3 \%)$, $19(10.9 \%), 15(8.6 \%), 4(\%), 6(3.4 \%), 3(2.3 \%), 24(13.7 \%)$ and $6(3.4 \%)$ of the patients. Complications such as DHF, DSS, AKI, and thrombocytopenia were found to be significantly more with higher grades of liver dysfunction while ARDS, DIC and multiorgan failure (MODS) were seen only in patients with grade D liver injury. This was found to be statistically significant by Fischer's exact test $(p=0.00001)$. None of the above complications were seen in patients with normal liver enzymes (Grade A) (Table 3 and Figure 6a-d).

Table 3: Association of grading of liver injury with various outcomes

\begin{tabular}{|c|c|c|c|c|c|}
\hline \multirow[b]{2}{*}{ S no } & \multirow[b]{2}{*}{ Complication/outcome } & \multicolumn{3}{|c|}{ Grading of liver injury } & \multirow[b]{2}{*}{$P$ value } \\
\hline & & $\begin{array}{l}\text { Grade B } \\
(n=85)\end{array}$ & $\begin{array}{l}\text { Grade C } \\
(n=29)\end{array}$ & $\begin{array}{l}\text { Grade D } \\
(n=19)\end{array}$ & \\
\hline 1 & DHF & $2(1.1 \%)$ & $23(13.1 \%)$ & $1(0.6 \%)$ & 0.00001 \\
\hline 2 & DSS & $2(1.1 \%)$ & $7(4 \%)$ & $10(5.7 \%)$ & 0.00001 \\
\hline 3 & AKI & $1(0.6 \%)$ & $4(2.3 \%)$ & $10(5.7 \%)$ & 0.00001 \\
\hline 4 & $\begin{array}{l}\text { Thrombocytopenia } \\
\text { (Platelets }<50,000 / \mathrm{cu} \mathrm{mm} \text { ) }\end{array}$ & $2(1.1 \%)$ & $2(1.1 \%)$ & $4(2.3 \%)$ & 0.0001 \\
\hline
\end{tabular}

Fischer's exact test was used to calculate the P value.

HF - Dengue Hemorrhagic Fever, DSS - Dengue Shock

Syndrome, AKI - Acute Kidney injury
A comparison of number of days of hospital and ICU stay was done between the four groups. It was found that longer duration of hospital and ICU stay were significantly associated with higher grades of liver dysfunction. ( $p$ value $=0.030)$ (Table 4)

Table 4: Association between duration of stay and grades of liver involvement $(\mathrm{N}=175)$

\begin{tabular}{|l|l|l|l|l|l|}
\hline Variable & Liver involvement grades & p value \\
\cline { 2 - 5 } & $\begin{array}{l}\text { Grade A } \\
\text { N }(\%)\end{array}$ & $\begin{array}{l}\text { Grade B } \\
\text { N }(\%)\end{array}$ & $\begin{array}{l}\text { Grade C } \\
\text { N }(\%)\end{array}$ & $\begin{array}{l}\text { Grade D } \\
\text { N }(\%)\end{array}$ \\
\hline $\begin{array}{l}\text { Duration of stay } \\
\text { 4-5 days }\end{array}$ & $17(40.5)$ & $5(20)$ & $17(19.1)$ & $1(5.3)$ & 0.030 \\
$6-10$ days & $25(59.5)$ & $19(76)$ & $71(79.8)$ & $18(94.7)$ & 0 \\
$>10$ days & 0 & $1(4)$ & $1(1.1)$ & & \\
\hline
\end{tabular}

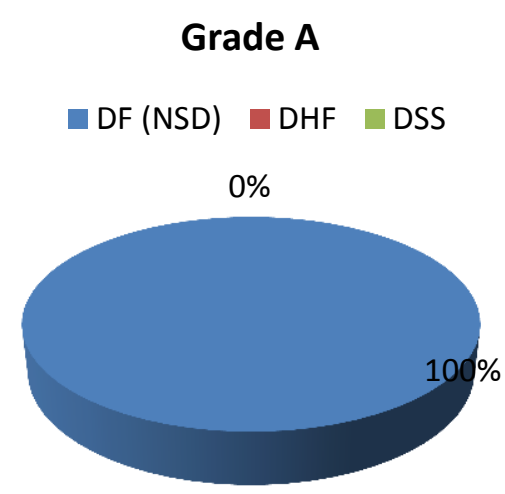

\section{Grade B} $\square \mathrm{DF}(\mathrm{NSD}) \quad \mathrm{DHF} \quad \mathrm{DSS}$

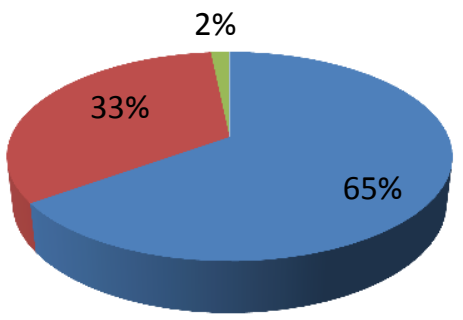




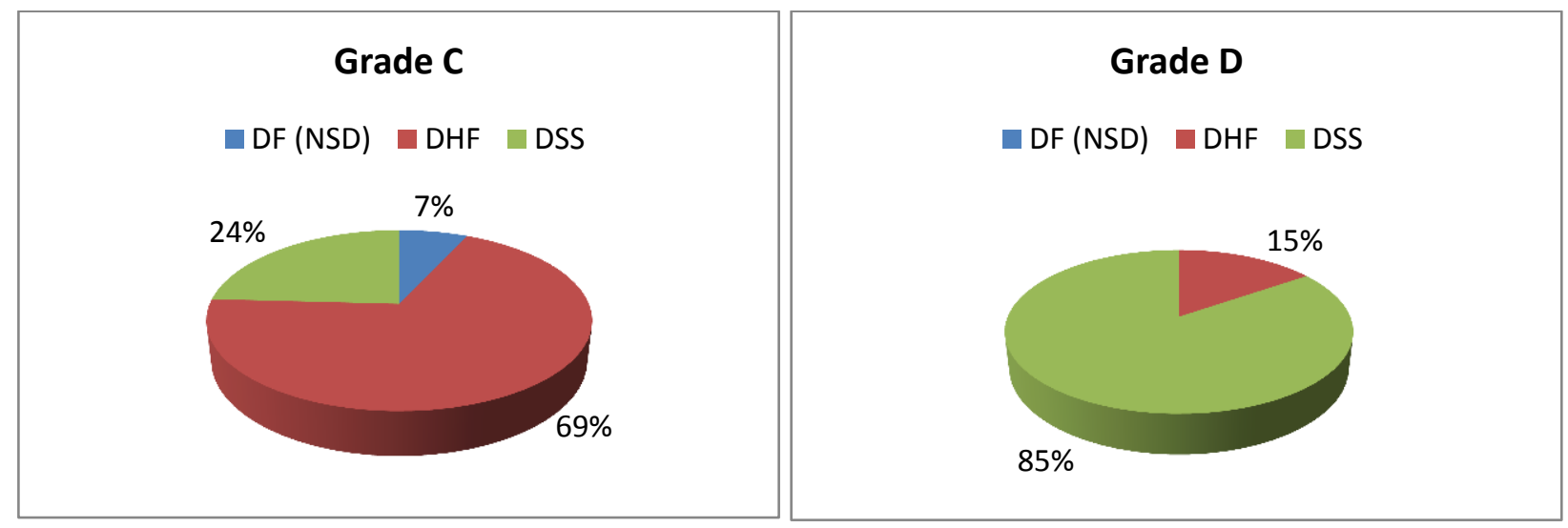

Figure 6 (a-d): Correlation of grading of liver injury with the severity of Dengue fever $(\mathrm{N}=175)$

\section{Discussion}

Dengue fever is an arboviral infectious disease with liver being the commonest organ to be involved. Hepatic damage is due to direct viral toxicity (viral cytopathy) or dysregulated immunologic response to the virus ${ }^{[5,8]}$. Autopsies of fatal cases have confirmed hepatocytes and Kupffer cells as the prime targets for DENV infection ${ }^{[5,10]}$.

Pathogenesis of hepatic injury in dengue is primarily a $\mathrm{T}$ cell mediated process involving interaction between antibodies and the endothelium, cytokine storm (cytokine "Tsunami") and host factors like genetic polymorphisms ${ }^{[11,12]}$. The kinetics of liver enzyme elevation correlates with that of T-cell activation. In addition, hypoxic insult to the liver due to hypoperfusion during shock also plays a role in liver injury ${ }^{[5]}$. Post mortem studies done in patients with SD have shown congested liver with hepatocyte apoptosis and necrosis predominantly, in mid-zonal and centrilobular areas, macrovascular steatosis and councilman bodies, with little inflammation ${ }^{[13,14]}$. The spectrum of involvement includes asymptomatic elevation of hepatic transaminases to acute liver failure (ALF) ${ }^{[5]}$. Although ALF is typically described in patients with prolonged shock in SD, ALF can also occur in absence of shock ${ }^{[6]}$. This study aimed at studying the profile of liver function tests and correlating the degree of liver dysfunction with morbidity and mortality and hence, use them as prognostic marker of the disease severity.

Liver damage has been found to be more common among females in the large study from Brazil by de Souza LJ et al $(74.6 \%$ of females vs $52.2 \%$ of males) ${ }^{[9]}$. However, studies by Soni A et al ${ }^{[12]}$ and Bagepally RS et al ${ }^{[15]}$ showed male preponderance (M:F ratio 2:1 and 2.5:1 respectively). Our study also showed slight overall male preponderance (M:F ratio 1.1:1) while the male to female ratio in patients with hepatic dysfunction was $2.8: 1$.

Study by Mukherjee $\mathrm{S}$ et al revealed majority $(69.5 \%)$ of the cases were in the age group of 16 to 30 years while the mean age was 27 years ${ }^{[16]}$. Similarly $50.9 \%$ of the cases in our study were in the age group of 16 to 30 years and the mean age was 32 $( \pm 13.06)$ years.

Clinical features of hepatic involvement found in various series were abdominal pain ( $18 \%$ to $63 \%$ ), nausea with or without vomiting (49\% to $58 \%)$ and anorexia $(31 \% \text { to } 44 \%)^{[16,17,18]}$. The frequency of hepatomegaly in adult patients ranged from $4 \%$ to $52 \%$. In a study by Saha $\mathrm{AK}$ et al, hepatomegaly was found in $49.8 \%$ of the patients and was significantly more in DHF than in DF $(p<0.01)^{[19]}$. Our study also revealed similar observation. Hepatomegaly was found in $34(19.4 \%)$ of cases and with higher grades of hepatic dysfunction. In a study by Chhina RS et al, hepatomegaly was more frequent in DSS group as compared to DF group $(45.5 \%$ vs $10.9 \%)(\mathrm{p}<0.05)^{[20]}$.

While clinical jaundice has been detected in $1.7 \%$ to $17 \%$, hyperbilirubinemia has been found in $48 \%$ of the patients in a study by Karoli $\mathrm{R}$ et al from North India ${ }^{[21]}$. Only $6(3.6 \%)$ patients in our study had clinical jaundice, 5(3\%) had serum bilirubin > 5mg/dl while hyperbilirubinemia was detected in $14(8.2 \%)$ cases. $16.3 \%$ cases had serum bilirubin $>5 \mathrm{mg} / \mathrm{dl}$ in the study by Saha AK et al. ${ }^{[19]}$

Literature review revealed that raised transaminase levels was the commonest biochemical abnormality. Increased AST levels was seen in $63 \%-97 \%$ of patients, while raised ALT levels in $45-96 \%$ of patients ${ }^{[5,17,18,22,23]}$. Elevation in AST was more than ALT, more during the first week of infection, with a tendency to decrease to normal levels within three weeks ${ }^{[5,23]}$. AST released additionally from the damaged myocytes may explain the higher levels of AST than those of ALT in these patients. Thus, increased AST/ALT ratio is useful for differential diagnosis of acute hepatitis caused by the hepatitis A, B or C viruses ${ }^{[5]}$. In a study by Uchadadia $S$ et al involving 200 patients, average AST levels $(171.27 \pm 190.03)$ were higher than average ALT levels $(144.71 \pm 162.77)^{[8]}$. This preferential elevation of AST over ALT was also noted in our study. Similarly, studies by de Souza LJ et al ${ }^{[22]}$, Chhina RS et al ${ }^{[20]}$ and Soni A et al ${ }^{[12]}$ also showed a greater elevation in AST than ALT levels.

Bagepally RS et al, in their study of 105 patients, found the significant difference in the degree of elevation in the liver enzymes in the survived $(n=93)$ and non-survived group $(n=12)$. Mean value of ALT was 260U/L (survived group) and 931U/L (mortality group), while the mean value of AST was 390U/L (survived group) and 1075U/L (mortality group) ${ }^{[15]}$. Similar findings were seen in our study, though the degree of elevation of AST and ALT in the non-survived group was far higher as seen in table 4.

Study by Chandrashekar et al ${ }^{[24]}$ observed that the serum albumin levels was significantly lower in confirmed dengue cases $(\mathrm{p}<0.03)$. In a study by Chhina RS et al, it was found that the serum albumin level was statistically lower in patients with DHF and DSS as compared to patients with DF $(p<0.01)^{[20]}$. Our study also showed a significant association between the severity of hepatic dysfunction and low serum albumin levels.

Study by Uchadadia $S$ et al showed high degree of correlation between the degree of liver damage and complications. It was observed that $77 \%$ of patients with DHF, $88 \%$ of patients with DSS and those with hepatic encephalopathy and acute renal failure had grade $C$ and D hepatic damage ${ }^{[8]}$. Similar results were seen in a study by Khan NA et al in Saudi Arabia in 2008 where an association was found between the complications and high AST 
levels ${ }^{[25]}$. The study by Kuo $\mathrm{CH}$ et al from Taiwan reported higher risk of bleeding in patients with higher levels of AST and ALT ${ }^{[17]}$. Kumar S et al, studied 100 patients of dengue fever and found that AST and ALT levels were statistically higher in those developing complications like ARDS, AKI, acute liver failure and encephalopathy ${ }^{[23]}$. In our study, we found a significant correlation between severity of hepatic dysfunction and complications like AKI, ARDS, bleeding manifestations, shock and MODS ( $\mathrm{p}<0.01)$. Study by Soni A et al also found, the degree of rise of AST, ALT and serum bilirubin was significantly higher in DHF and DSS, as compared to DF ${ }^{[12]}$. A study was done by Prashant VN et al involving 100 patients, GI bleed, ascites, jaundice and correlated with elevation of transaminases and thus, severity of dengue fever [18]. Study by Ahmad A et al revealed increasing trend in complications like septicemia, hepatic failure, hemorrhage, renal failure and mortality with higher grades of hepatic dysfunction ${ }^{[26]}$.

\section{Conclusion}

Hepatic dysfunction is a common feature seen in patients suffering from dengue fever. In a patient with febrile illness, elevated AST more than the ALT may give a clue to the possibility of dengue fever. Peak rise occurs between fifth to ninth day of illness. Also, the severity of hepatic dysfunction is seen to correlate with mortality and morbidity parameters, with higher grades of hepatic dysfunction being associated with higher rates of complications such as DHF, DSS, ICU admissions, an increased length of hospital stay and higher mortality. Elevation of liver enzymes can therefore, be used for early recognition and prediction of severity of dengue fever.

\section{Conflict of interest}

There is no conflict of interest

\section{Source of funding}

There is no funding source

\section{Consent of the patients}

Informed consent has been taken from all the participants at the beginning of the study

\section{Author contributions}

Kamath SD - Data analysis, data interpretation, drafting, and statistical analysis

Ahmed T - Data collection, literature search

The authors give consent for publication in case the article is found suitable.

\section{References}

[1] Guzman MG, Halstead SB, Artsob H, Buchy P, Farrar J, Gubler DJ, Hunsperger E, Kroeger A, Margolis HS, Martínez E, et al. Dengue: a continuing global threat. Nat Rev Microbiol. 2010;8:S7-16. doi: 10.1038/nrmicro2460

[2] Guzmán MG, Kourí G. Dengue: an update. Lancet Infect Dis. 2002;2:33-42. doi: 10.1016/s1473-3099(01)001712.
[3] World Health Organization. Dengue: guidelines for diagnosis, treatment, prevention and control, New Edition. Geneva: World Health Organization Publishers; 2009. p. 4-6. Available from: http://www.who.int/tdr/publications/documents/denguediagnosis.pdf

[4] Trung DT, le Thao TT, Hien TT, Hung NT, Vinh NN, Hien PT, et al. Liver involvement associated with dengue infection in adults in Vietnam. Am J Trop Med Hyg. 2010;83:774-80. doi: 10.4269/ajtmh.2010.10-0090

[5] Samanta J, Sharma V. Dengue and its effects on liver. World J Clin Cases. 2015;3(2):125-31. doi: 10.12998/wjcc.v3.i2.125

[6] Fernando S, Wijewickrama A, Gomes L, Punchihewa CT, Madusanka SDP, Dissanayake H, et al. Patterns and causes of liver involvement in acute dengue infection. BMC Infectious Diseases. 2016; 16:319-27.doi: 10.1186/s12879-016-1656-2

[7] Martina BE, Koraka P, Osterhaus AD. Dengue virus pathogenesis: an integrated view. Clin Microbiol Rev. 2009;22(4):564-81. doi:10.1128/CMR.00035-09

[8] Uchadadia S, Ghodke B, Bhuta K, Kejriwal A, Ghanekar J. Impairment of Liver Function in Dengue Fever correlates to the severity of its complications. MGM J Med Sci 2015;2(3):115-9.

[9] de Souza LJ, Nogueira RM, Soares LC, et al. The impact of dengue on liver function as evaluated by aminotransferase levels. Braz J Infect Dis. 2007; 11: 407 10. doi: 10.1590/s1413-86702007000400007

[10] Chen Y, Maguire T, Marks RM. Demonstration of binding of dengue virus envelope protein to target cells. J Virol 1996; 70: 8765-72. doi: 10.1128/JVI.70.12.87658772.

[11] Huerre MR, Lan NT, Marianneau P, et al. Liver histopathology and biological correlates in five cases of fatal dengue fever in Vietnamese children. Virchows Arch 2001; 438: 107-15. doi: 10.1007/s004280000329.

[12] Soni A, Patel P, Malhi N, Avasthi G.Spectrum of liver dysfunction in patients with dengue infection and markers of severe disease: Study from a tertiary care centre in Punjab. J Liver Res Dis Ther. 2017;3:00063. doi: 10.15406/jlrdt.2017.03.00063

[13] Mukherjee S, Manna K, Chatterjee P, Datta P, Datta S. Dengue fever and its epidemiological characteristics: A study from eastern India. Int $\mathbf{J}$ Comm Med Pub Heal. 2016;3(12):3588-94. doi: 10.18203/23946040.ijcmph20164297

[14] Parkash O, Almas A, Jafri SM, Hamid S, Akhtar J, Alishah H. Severity of acute hepatitis and its outcome in patients with dengue fever in a tertiary care hospital Karachi, Pakistan (South Asia) BMC Gastroenterol. 2010;10:43. doi: 10.1186/1471-230X-10-43

[15] Bagepally RS, Rao GS, Reddy BS, Kumar BV, Reddy BV, Reddy SJ, et al. Prognostic value of hepatic dysfunction in dengue infection. $\mathbf{J}$ Clinic and Exp Hepato. 2013;3(10)S119. doi:https://doi.org/10.1016/j.jceh.2013.03.208

[16] Mukherjee S, Manna K, Chatterjee P, Datta P, Datta S. Dengue fever and its epidemiological characteristics: A study from eastern India. Int J Comm Med Pub Heal. 2016;3(12):3588-94. doi: 10.18203/23946040.ijcmph20164297 
[17] Kuo CH, Tai DI, Chang-Chien CS, Lan CK, Chiou SS, Liaw YF. Liver biochemical tests and dengue fever. Am J Trop Med Hyg. 1992;47:265-70. doi: 10.4269/ajtmh.1992.47.265

[18] Prashanth VN, Manasa G. Study of gastrointestinal manifestations in Dengue fever. Int $\mathrm{J}$ Adv Med 2019;6:1476-81. doi: http://dx.doi.org/10.18203/23493933.ijam20194135

[19] Saha AK, Maitra S, Hazra SCh. Spectrum of hepatic dysfunction 2012 dengue epidemic in Kolkata, West Bengal. Indian J Gastroenterol 2013; 32: 400-3. doi: 10.1007/s12664-013-0382-6

[20] Chhina RS, Goyal O, Chhina DK, Goyal P, Kumar R, Puri S. Liver function tests in patients with dengue viral infection. Dengue Bulliten 2008; 32:110-7. https://apps.who.int/iris/handle/10665/170475

[21] Karoli R, Fatima J, Siddiqi Z, Kazmi KI, Sultania AR. Clinical profile of dengue infection at a teaching hospital in North India. J Infect Dev Ctries 2012; 6: 551-4. doi: 10.3855/jidc. 2010 .

[22] de Souza LJ, Gonçalves Carneiro H, Souto Filho JT, Ferreira de Souza T, Azevedo Côrtes V, et al. Hepatitis in dengue shock syndrome. Braz J Infect Dis 2002;6:3227. doi: $10.1590 / \mathrm{s} 1413-86702002000600010$

[23] Kumar S, Amit Basu A. Study of hepatic dysfunction in dengue fever. International Journal of Biomedical and Advance Research 2016; 7(8): 397-401. doi:10.7439/ijbar

[24] Chandraswkhar KT, Dutta TK, Arun Kumar R, Lokesh S, Pravin Charles MV. Evaluation of hepatocellular dysfunction and its association with severity in dengue infection. Int J Adv Med. 2019;6(3):639-45. doi: 10.18203/2349-3933.ijam20191487

[25] Khan NA, Azar EI, Ei-Fiky S, Madani HH, Abulijadial MA, Ashshi AM et al. Clinical profile and outcome of hospitalized patients during first outbreak of dengue in Makkah, Saudi Arabia. Acta Trop 2008; 105(1):39-44. doi:10.1016/j.actatropica.2007.09.005

[26] Ahmed A, Alvi A, Butt A, Nawaz A, Hanif AA. Assessment of Dengue Fever Severity Through Liver Function Tests. J Coll Physicians Surg Pak 2014,24 (9): 640-4. PMID: 25233967ticle 